\title{
ENHANCEMENT OF QUANTUM EFFICIENCY IN InGaN QUANTUM WELLS BY USING SUPERLATTICE INTERLAYERS AND PULSED GROWTH
}

\author{
K. Nomeika, M. Dmukauskas, R. Aleksiejūnas, P. Ščajev, S. Miasojedovas, A. Kadys, \\ S. Nargelas, and K. Jarašiūnas \\ Institute of Applied Research, Vilnius University, Saulètekio 9, LT-10222 Vilnius, Lithuania \\ E-mail: kazimieras.nomeika@tmi.vu.lt
}

Received 22 June 2015; revised 21 July 2015; accepted 29 September 2015

\begin{abstract}
Enhancement of internal quantum efficiency (IQE) in InGaN quantum wells by insertion of a superlattice interlayer and applying the pulsed growth regime is investigated by a set of time-resolved optical techniques. A threefold IQE increase was achieved in the structure with the superlattice. It was ascribed to the net effect of decreased internal electrical field due to lower strain and altered carrier localization conditions. Pulsed MOCVD growth also resulted in twice higher IQE, presumably due to better control of defects in the structure. An LED (light emitting diode) structure with a top p-type contact GaN layer was manufactured by using both growth techniques with the peak IQE equal to that in the underlying quantum well structure. The linear recombination coefficient was found to gradually increase with excitation due to carrier delocalization, and the latter dependence was successfully used to fit the IQE droop.
\end{abstract}

Keywords: light emitting diodes, nitride semiconductors, photoluminescence, carrier recombination, carrier diffusion PACS: 73.21.Fg, 78.67.-n, 78.47.-p

\section{Introduction}

GaN-based structures for light emitting diodes (LEDs) and other optoelectronic devices are grown predominantly on sapphire substrates by the MOCVD technique, because GaN substrates for homoepitaxial growth remain to be expensive and difficult to obtain. A large mismatch of the lattice constants and the thermal expansion coefficients between $\mathrm{GaN}$ and sapphire result in considerable strain, which in turn gives rise to a large amount of dislocations and an internal piezoelectric field. The high internal electric field quenches the internal quantum efficiency (IQE) in GaN-based quantum structures due to the quantum confined Stark effect. Therefore, several technological modifications of the LED structure have been developed to relieve the strain in the material. Most of these approaches involve inserting a buffer layer between the sapphire wafer and LED active structure, like a low-temperature GaN layer [1], AlN or AlGaN layer [2], $\mathrm{SiO}_{2}$ layer with openings for overgrowth [3], or a short period superlattice (SL) [仼. It has been demonstrated that the SL insertion layer results in increase of IQE smaller photoluminescence (PL) peak shift with injection [4] due to supposedly smaller defect density and lower internal electrical fields. SL was also used to improve the electroluminescence due to better hole injection and current spreading [7-9].

On the other hand, IQE depends on structural quality of InGaN quantum wells that determine the amount of defects and, consequently, nonradiative recombination time. It is well known that IQE drops as the In content is increased, mostly due to lower growth temperatures needed to achieve larger In amount in the layers. A promising technique for achieving metal rich InGaN layers of good quality is a pulsed growth. This technique was mainly used for InN growth, but it has also been demonstrated as a promising tool for InGaN growth by metal-modulated epitaxy [10], highpressure MOCVD [11, 12], and recently by low pressure MOCVD [13].

In this paper, we analyze the effects of SL insertion and the pulsed growth on IQE by monitoring carrier dynamics in the InGaN quantum well (QW) structures 
emitting at 450-460 nm. Optical properties and carrier dynamics features are compared between (i) QW structures with and without an SL interlayer and (ii) identical QW samples grown by continuous or pulsed growth. We employ a number of time-resolved techniques like light-induced transient gratings (LITG), differential transmission (DT), free carrier absorption (FCA), and photoluminescence (PL) to obtain a detailed picture of carrier recombination pathways. We demonstrate a three-fold increase in IQE in the structure with an SL and a two-fold one in the pulsed grown sample, as compared to that of the corresponding reference structures. We analyze the effects of changes in the internal electrical field and carrier delocalization on the IQE in the structures. We also demonstrate that a full LED structure with a p-contact layer may reach the peak IQE equal to that of the underlying MQW structure.

\section{Samples and measurement techniques}

Two sets of MQWs structures under investigation were grown by MOCVD on (0001) sapphire with a $\sim 3 \mu \mathrm{m}$ thick $\mathrm{GaN}$ template. Ammonia $\left(\mathrm{NH}_{3}\right)$, trimethylgallium (TMG), trimethylindium (TMI), trimethylaluminum (TMA), silane, and magnesium bispentacyclodienyl $\left(\mathrm{Cp}_{2} \mathrm{Mg}\right)$ were used as source compounds, nitrogen and hydrogen were used as carrier gases.

In the first set of MQWs samples (samples $A$ and $B$ ) we investigated an impact of InGaN/GaN SL as a crystal grating stress modified interlayer between the GaN template and MQWs. The SL growth parameters in sample $A$ were optimized: the SL structure consists of 8 periods of $\operatorname{In}_{0.06} \mathrm{Ga}_{0.94} \mathrm{~N} / \mathrm{GaN}$ heterostructures with a total thickness of $30-35 \mathrm{~nm}$. The active regions of the structures contained five (3-4) nm wide $\mathrm{In}_{0.1} \mathrm{Ga}_{0.9} \mathrm{~N}$ QWs separated by $6 \mathrm{~nm}$ wide $\mathrm{GaN}$ quantum barriers. The whole structure is capped by a $30 \mathrm{~nm}$ thick GaN layer. Sample $B$ was grown under identical conditions, but without SL.

In the second set of 3 samples (samples 1,2,3) we analyzed impact of the pulsed growth on QW and full LED quantum efficiency. All samples were grown on a $3 \mu \mathrm{m}$ thick GaN template on sapphire together with an optimized SL interlayer which has been described above. The active part consisted of 5 periods $\mathrm{In}_{0.1} \mathrm{Ga}_{0.9} \mathrm{~N} / \mathrm{GaN}$ multiple QW structure 3-4 nm thick wells and $6 \mathrm{~nm}$ thick barriers. A reference InGaN/GaN MQW structure (sample 1) was grown in a conventional precursor continuous-flux mode. In the pulsed growth mode, $\mathrm{NH}_{3}$ was constantly flowing, while TMI and TMG were sent into a chamber for $15 \mathrm{~s}$, and then bypassed for $5 \mathrm{~s}$ (sample 2). More details of the pulsed growth MOCVD can be found in Ref. [14]. Finally, a full LED structure with a top $40 \mathrm{~nm}$ thick $p$-type $\mathrm{Al}_{0.1} \mathrm{Ga}_{0.9} \mathrm{~N}$ blocking layer and a $300 \mathrm{~nm}$ thick $p$-type GaN layer was grown (sample 3).

The experimental set-up for the time-resolved DT consisted of a PHAROS (Light Conversion) laser, delivering $1030 \mathrm{~nm}$ and $200 \mathrm{fs}$ duration pulses at the $30 \mathrm{kHz}$ repetition rate and an ORPHEUS (Light Conversion) optical parametric amplifier (OPA), generating wavelengths in the $630-2600 \mathrm{~nm}$ range. Frequency doubling of OPA pulses was used to set the wavelength of one of the split beams from the laser for the selective excitation $(382 \mathrm{~nm}, 3.25 \mathrm{eV})$ of the QWs in the samples while the other delayed beam was passed through a sapphire crystal to generate a white light continuum probe. A spectrograph with the 300 lines/mm grating and a CCD camera spectrometer provided means to observe the evolution of DT spectra in a $380-480 \mathrm{~nm}$ window. A chopper was used to periodically close the pump pulse and measure the DT with and without excitation $\left(T_{\mathrm{p}}(\lambda, t)\right.$ and $T_{0}(\lambda)$, respectively) at various probe delays, providing the instantaneous $T(\lambda, t)$ spectra (in mOD units): $T(\lambda, t)=1000 \times \log \left(T_{0}(\lambda) / T_{\mathrm{p}}(\lambda, t)\right)$.

FCA and PL IQE measurements were carried out using the same laser system as in DT. In FCA, the second OPA was used for a probe beam. The probe was tuned to $1.65 \mu \mathrm{m}(0.75 \mathrm{eV})$. An integrating sphere with the three-measurement approach was used for the evaluation of PL IQE [15]. In the three-measurement approach 3 PL spectra are taken: one with an empty sphere, one with the sample in the sphere but out of the path of the pump beam and one with the sample in the sphere and in the path of the pump beam. For both experiments, the pump was $390 \mathrm{~nm}(3.18 \mathrm{eV})$.

The YAG: $\mathrm{Nd}^{3+}$ laser with 25 ps pulse duration and $10 \mathrm{~Hz}$ repetition rate was combined with a Hamamatsu C10627 streak camera and an Acton SP2300 monochromator for TRPL measurements, providing a temporal resolution of $20 \mathrm{ps}$. With the water Raman-shift of the third laser harmonic ( $355 \mathrm{~nm})$ the wavelength of the pump beam was $405 \mathrm{~nm}(3.06 \mathrm{eV})$.

For the LITG experiment, the same YAG:Nd ${ }^{3+}$ laser with the water Raman-shifted pump to $405 \mathrm{~nm}$ was used. The principle of the technique is the excitation of the sample by an interference field of two coherent pump beams, creating a transient spatially modulated free carrier pattern $N(x)=N_{0}+\Delta N[1+\cos (2 \pi x / \Lambda)]$ with spacing $\Lambda$, which modulates the refractive index $\Delta n(x) \propto \Delta N(x)$ and diffracts a delayed probe beam $(1064 \mathrm{~nm}-1.17 \mathrm{eV}$, fundamental laser harmonic). Diffraction efficiency of a transient grating $\eta(t) \propto(\Delta N d)^{2}$ and its decay $1 / \tau_{\mathrm{g}}=1 / \tau_{\mathrm{R}}+1 / \tau_{\mathrm{D}}$ provided a convenient way to determine the recombination-governed 
grating decay time $\tau_{\mathrm{R}}$ and the diffusive decay time $\tau_{\mathrm{D}}=\Lambda^{2} /\left(4 \pi^{2} D_{\mathrm{a}}\right)$. The latter is $\Lambda$ dependent, therefore the bipolar diffusion coefficient $D_{\mathrm{a}}$ was determined by performing measurements with different induced grating periods at various photoexcited carrier densities.

The reflectivity of the samples was 0.3 for the FCA experiment (because of the Brewster's angle of the sample in respect of the pump beam) and 0.2 for other techniques. For the calculations of photoexcited carrier densities the absorption coefficient $\alpha=10^{5} \mathrm{~cm}^{-1}$ was taken, which resulted in $1.35 \times 10^{19} \mathrm{~cm}^{-3}$ for the $100 \mu \mathrm{J} /$ $\mathrm{cm}^{2}$ excitation energy fluence.

\section{Results and discussion}

Figure 1 (a) shows the IQE as a function of photoexcited carrier density in the samples with and without an SL layer. Both IQE curves reveal the typical features of "efficiency droop" in InGaN QWs: the IQE value increases up to carrier densities of $(1-3) \times 10^{19} \mathrm{~cm}^{-3}$ and starts to decline at higher excitations. SL insertion resulted in threefold increase of the peak IQE value (30\% in sample $A$ versus $10 \%$ in sample $B$ ) and much

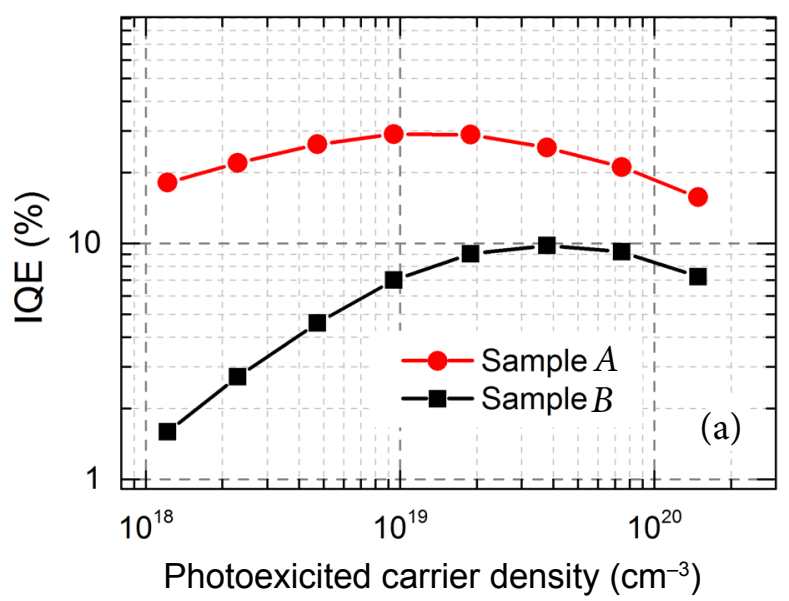

"flatter" IQE vs the excitation curve. We note a rather large blueshift of the PL peak position with excitation in sample $B(170 \mathrm{meV})$, compared to the shift by $40 \mathrm{meV}$ in sample $A$ (Fig. 1(b)). Consequently, a full width at the half maximum (FWHM) of the PL spectrum in sample $B$ became considerably broader at high excitations, while at low ones the FWHM values were similar in both structures (Fig. 1. 1(c)). Different blueshift and emission wavelengths can be attributed to the effects of the internal electrical field. A larger blueshift with excitation indicates a stronger internal piezo electrical field in sample $B$ due to larger strain, while much shorter emission wavelengths at high carrier densities point out a smaller indium amount in this structure. The reported strain relaxation due to the SL [4] and slower indium incorporation in the compressively strained QWs [16] support the latter assumption. In addition, TEM and XRD data (to be reported elsewhere) suggest that the QW growth rate is larger in more strained structures. As a result, thinner QWs with higher In content can be expected in sample $A$, which is favourable for higher IQE [17, 18] and smaller efficiency droop. The impact of

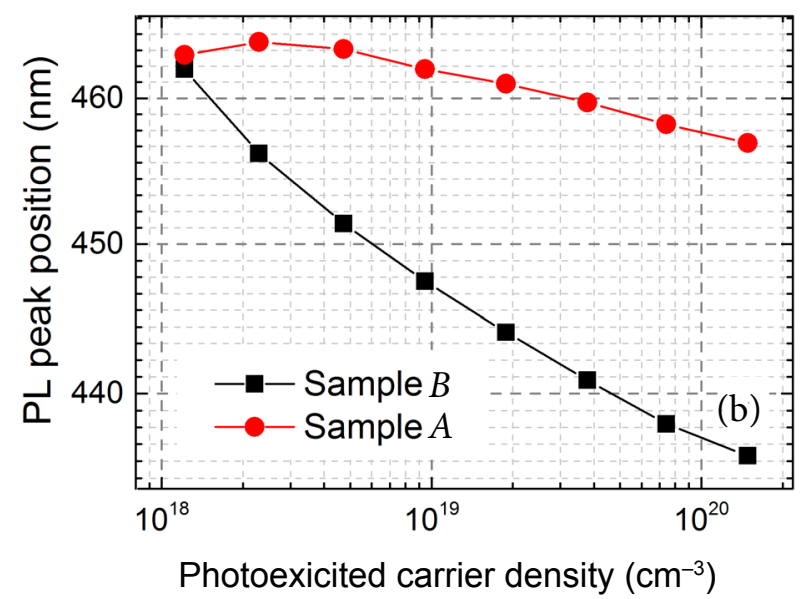

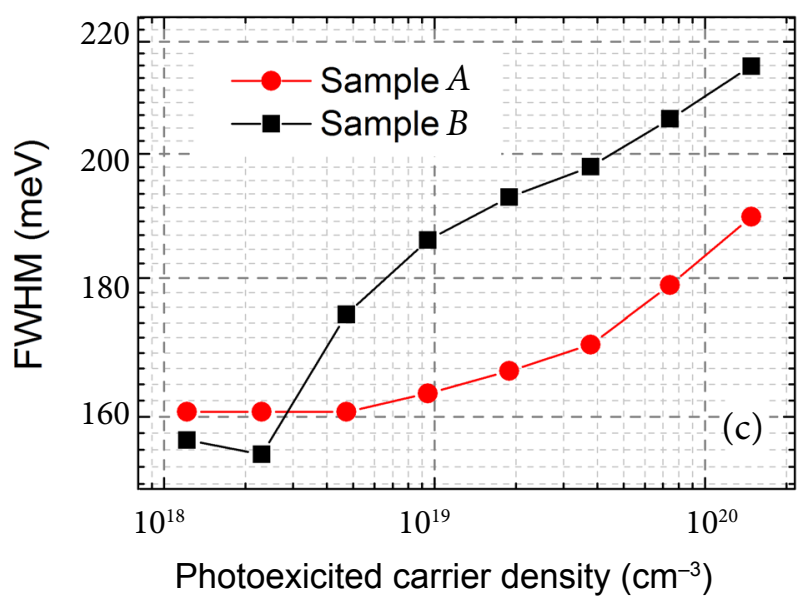

Fig. 1. Photoluminescence quantum efficiency (a), peak position of PL spectra (b), and FWHM (c) as a function of photoexcited carrier density in the structures with SL (sample $A$, red online) or without SL (sample $B$, black). 
the internal electrical field, however, cannot fully account for differences in IQE, especially at high carrier densities. Also, large PL peak shift can be caused by saturation of localized states at a low energy side of the PL spectrum [19-22].

Time-resolved FCA, PL, and DT measurements were carried out for a direct observation of carrier dynamics and discrimination between the radiative and non-radiative recombination pathways. The FCA technique allowed determination of the average lifetime of the net carrier population, while DT provided complementary information on temporal changes in the occupancy of particular states. Figure 2(a) shows the FCA kinetics recorded in sample $A$ for various excitation energy densities within the $30-890 \mu \mathrm{J} / \mathrm{cm}^{2}$ range. The peak amplitude of the transients increases linearly with the carrier density within the entire excitation range, thus confirming a linear increase of the photoexcited carrier density and the absence of absorption bleaching. A precise calibration of the carrier density $N$ and density-dependent recombination constants of the $A B C$ model [23] is feasible under this condition. For the sake of estimation simplicity, an instantaneous decay time at the very initial part of the kinetics (within $90-200$ ps after the pump) was calculated as a function of $N$ (Fig. 2(b)). The latter dependence revealed a close to the linear decrease of lifetime with excitation which may be attributed either to the increase of the radiative recombination rate $\left(1 / \tau_{\mathrm{rad}} \sim B_{\mathrm{rad}} N\right.$, where $B_{\text {rad }}$ is the radiative recombination coefficient) or to the density-activated nonradiative recombination after carriers escape from the potential minima and are captured by traps [24], which can be expressed by the nonradiative recombination rate $A(N)=B_{n r} N$. If both processes take place simultaneously, only a part of the total density-dependent recombination rate can contribute

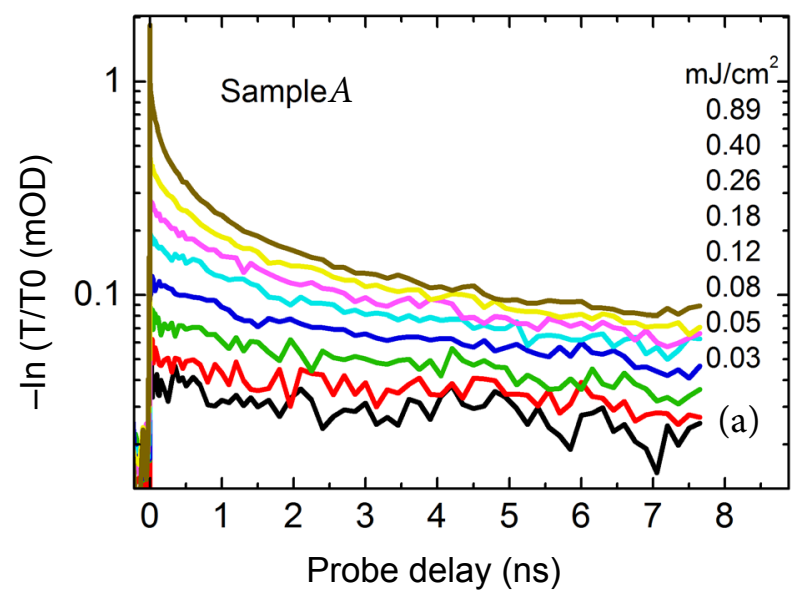

to the radiative decay, i. e. $B^{*}=B+B_{\mathrm{nr}}$, in agreement with our previous observations [25, 26].

We applied the described models for the analysis of the excitation-dependent carrier lifetime. Following the standard ABC model, the constant non-radiative recombination coefficient $A$ (or excitation-independent nonradiative lifetime $\tau_{\mathrm{NR}}=1 / A$ ) and the effective recombination coefficient $B^{\star} \sim 1 / N$ can be obtained from the fitting of the decay time $\tau=\left(A+B^{\star} N+C N^{2}\right)^{-1}$, where $C$ is the Auger recombination term. The Auger term is considered as a possible mechanism of non-radiative losses; however, it should be important only at carrier densities well above $10^{19} \mathrm{~cm}^{-3}$ due to a small value $\left(\sim 10^{-31} \mathrm{~cm}^{6} / \mathrm{s}\right)$ in $\mathrm{InGaN}$ [27]. For both samples $\tau_{\mathrm{NR}}=1 / A \approx 35 \mathrm{~ns}$ was estimated from TRPL transients at long delay times ( $>30 \mathrm{~ns}$ ); this term is dominant at carrier densities below $10^{18} \mathrm{~cm}^{-3}$. The values of the recombination coefficient $B^{\star}$ were estimated from Fig. 2(b) as $0.8 \times 10^{-11} \mathrm{~cm}^{3} / \mathrm{s}$ and $2.4 \times 10^{-11} \mathrm{~cm}^{3} / \mathrm{s}$ for samples $B$ and $A$, respectively. The ratio of three between the $B^{\star}$ as well the IQE values agrees quite well for these samples, suggesting that competition between the radiative and nonradiative processes varies with excitation and depends on the sample structural quality. On the other hand, different IQE values may be a consequence of different density of carriers contributing to radiative recombination. We fitted the measured IQE curves with the modified $\mathrm{AB}^{\star} \mathrm{C}$ model:

$$
\mathrm{IQE}=\frac{B_{\mathrm{rad}} N}{A+\left(B_{\mathrm{rad}}+B_{\mathrm{nr}}\right) N} .
$$

To better account for the IQE droop, saturation of $B_{\text {rad }}$ with the excitation due to the phase-state filing was included [28]:

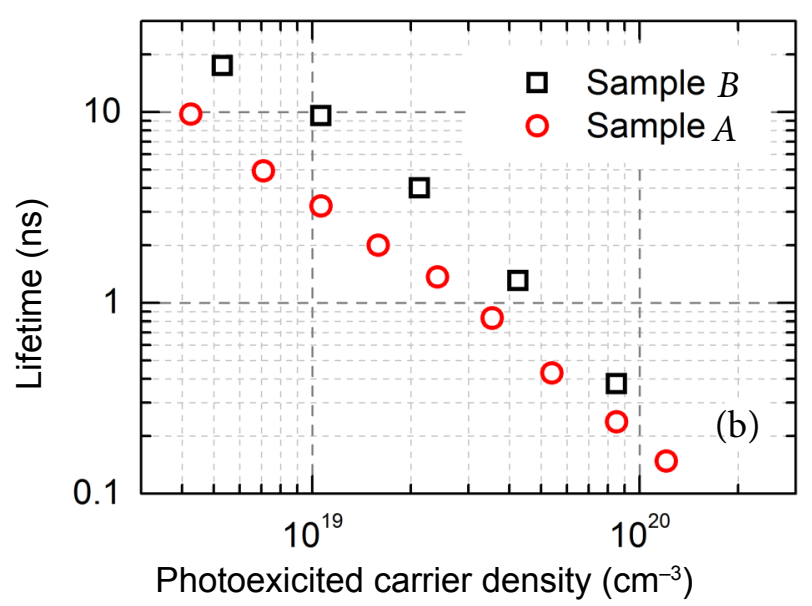

Fig. 2. (a) FCA kinetics in sample $A$ at various excitations. (b) Instantaneous carrier lifetime at $100-200$ ps delay as a function of photoexcited carrier density. 


$$
B_{\text {rad }}=\frac{B_{0}}{1+\frac{N}{N^{*}}} .
$$

Here, $B_{0}$ is the unsaturated recombination coefficient and $N^{*}$ is the threshold carrier density of saturation. $B^{*}=B_{\mathrm{rad}}+B_{\mathrm{nr}}=$ const was also assumed since FCA measurements showed no saturation of the net $B^{*}$ term. A good fit of IQE curves was obtained under these assumptions, without adding the Auger term (Fig. 3). Equation (1) allowed obtaining exact absolute IQE values, while the standard $A B C$ with the $C$ term of $2 \times 10^{-31} \mathrm{~cm}^{6} / \mathrm{s}$ yields in an overestimated IQE. Fitting parameters were as follows: $1 / A=26 \mathrm{~ns}, B^{\star}=2.4 \times 10^{-11}$, $N^{*}=9.4 \times 10^{19} \mathrm{~cm}^{-3}, \quad B_{0}=0.9 \times 10^{-11} \mathrm{~cm}^{3} / \mathrm{s}$ (sample $A) ; 1 / A=15 \mathrm{~ns}, B^{\star}=0.8 \times 10^{-11}$, $N^{*}=20 \times 10^{19} \mathrm{~cm}^{-3}, B_{0}=0.11 \times 10^{-11} \mathrm{~cm}^{3} / \mathrm{s}$ (sample $B$ ). Net $B^{*}$ values were taken from the fit in Fig. 2(b). The analysis of Eq. (1) shows that the peak IQE value is governed by the ratio of $B_{\mathrm{rad}} / B_{\mathrm{nr}}$ : this ratio is 0.6 and 0.16 in samples $A$ and $B$, which correlates with the IQE peak values of 30 and $10 \%$. The efficiency droop occurs due to the expected saturation of $B$ and predominantly due to the increase of $B_{\mathrm{nr}}$ [26, 30]. The initially constant $A$ term, being relatively small in the samples, has some impact only at lower excitations. Different values of the radiative recombination efficiency $B_{\text {rad }}$ in the samples can be attributed to the quantum confined Stark effect: stronger electrical field results in larger separation of electron-hole wave functions and smaller radiative recombination in sample $B$. We note that $N^{*}$ values can also be affected by the electrical field, since it is not accounted for in the simplistic model (1).

To assess the physical reasons behind the lower radiative recombination rate in sample $B$, we measured and compared the PL and DT spectra at various excitations and delay time instants (Fig. 4). The DT

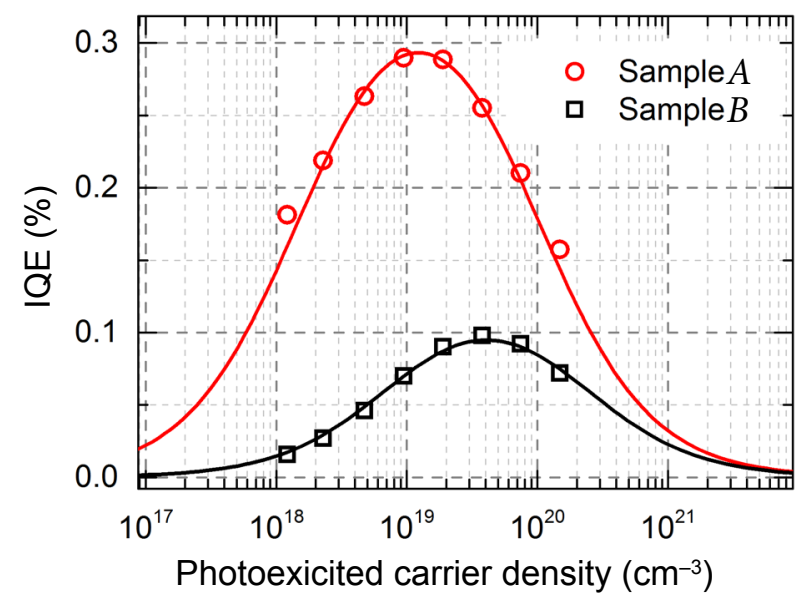

Fig. 3. Fitted IQE curves using the (1) model.
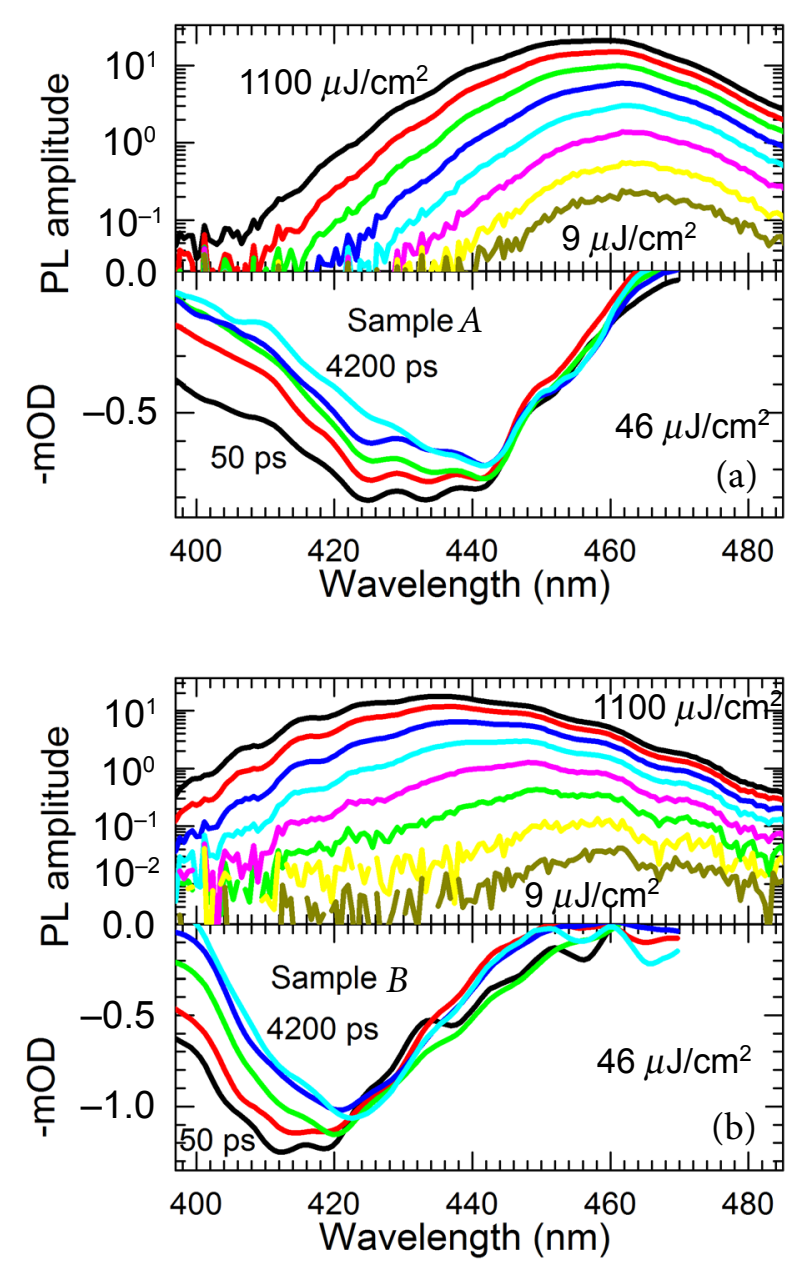

Fig. 4. Time-integrated PL spectra at various excitations (top figures, excitation range is indicated on the plot) and differential transmission (DT) spectra at various delay times (bottom figures) in samples with SL (a) and without SL (b).

signal has a negative sign indicating the bleaching of absorption in the bandgap vicinity. A shift between the spectral positions of DT and PL spectra indicates that absorption occurs in higher energy states (presumably in the extended states of a QW), then carriers relax in low energy localized states, where radiative recombination occurs. An overlap between the DT and PL spectra pointed out to the most efficient spectral range of carrier transfer from high to low energy states. This process may influence the PL efficiency, since the PL efficiency from the high energy states is low if compared to that from the localized low energy states [31]. At the $46 \mu \mathrm{J} / \mathrm{cm}^{2}$ excitation (corresponding to $6.2 \times 10^{18} \mathrm{~cm}^{-3}$ carrier density), the shift between PL and DT spectra is 25 and $31 \mathrm{~nm}$ in samples $A$ and $B$, respectively. Larger separation between the absorption and PL peaks results in smaller IQE in sample $B$, especially at lower excess carrier densities. With increasing excitation, 
the PL spectra broaden as the localized states get saturated and the fast PL transients point to emission from the higher energy. This broadening is larger in sample $B$ (Fig. 1(c)), pointing out to lower density of the localized states in it with respect to sample $A$.

Stronger carrier localization in sample $A$ is further evidenced by the dependence of the diffusion coefficient $D$ on carrier density (Fig. 5). $D$ is equal to $0.5 \mathrm{~cm}^{2} / \mathrm{s}$ and $1 \mathrm{~cm}^{2} / \mathrm{s}$ at carrier density of $1 \times 10^{19} \mathrm{~cm}^{-3}$ in samples $A$ and $B$, respectively. It increases with excitation in both samples, but the increase is more pronounced in sample $B$. LITG gives the bipolar diffusion coefficient, which under the used experimental conditions is proportional to the hole mobility [32]. We explain higher mobility of free carriers (holes) in sample $B$ by a larger part of free carriers occupying the extended states in QWs, as compared to that of sample $A$. With increasing excitation, a relatively larger part of carriers is being transferred to the extended states, and this is reflected in asymmetrical broadening of DT and PL spectra towards higher energies. A similar effect has been reported previously [26]. Therefore, it can be suggested that larger increase in the $D$ value is also a signature of faster non-radiative recombination and, thus, lower IQE at high excitations. Delocalization of presumably holes and subsequent increase of non-radiative recombination of carriers with increasing density is the physical origin of the term $B_{\mathrm{nr}}$ and a possible reason for IQE droop.

An impact of the pulsed MOCVD growth on the IQE of QW structures was investigated by performing similar measurements of IQE, time-resolved PL, DT spectra, and LITG kinetics. Here a set of 3 samples was analyzed.

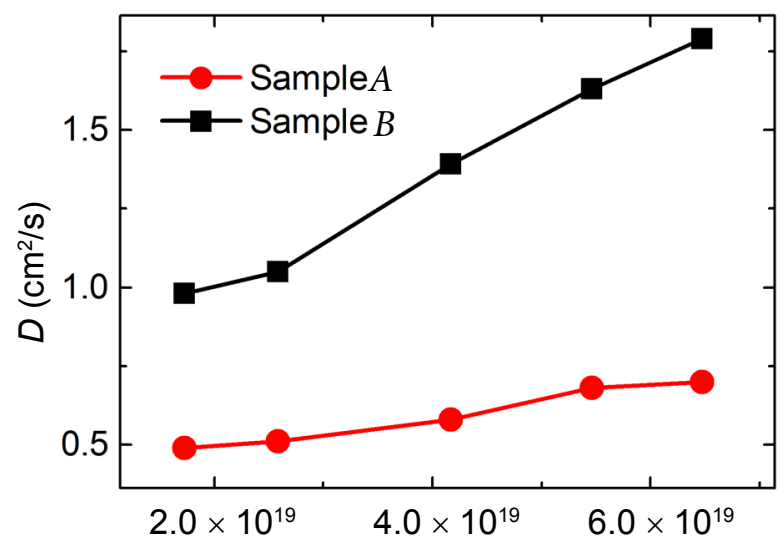

Photoexicited carrier density $\left(\mathrm{cm}^{-3}\right)$

Fig. 5. Diffusion coefficient as a function of photoexcited carrier density.
Figure 6(a) shows the comparison of IQE in the samples grown under continuous or pulsed growth mode (sample 1 and sample 2, respectively). The pulsed growth resulted in almost twofold IQE increase with respect to the reference structure. In contrast to the previous set, the peaks of the IQE curves appear at similar carrier density of $\sim 2 \times 10^{19} \mathrm{~cm}^{-3}$ in both samples. This value is close to that in sample $A$, which confirms that the droop threshold density is closely related to the structure of the sample, since the latter determines the strain, internal electrical field strength, and carrier localization. The latter is weaker in the reference structure, as evidenced by higher carrier diffusivity with respect to the pulsed growth structure (Fig. 6(b)). Moreover, even slightly weaker carrier localization and higher $D$ value in the LED structure lead to its low IQE value at low excitations (sample 3). The LED structure also exhibits larger PL blueshift with excitation $(\sim 70 \mathrm{meV})$ if compared to sample $2(30 \mathrm{meV}$, Fig. 7). Similarly
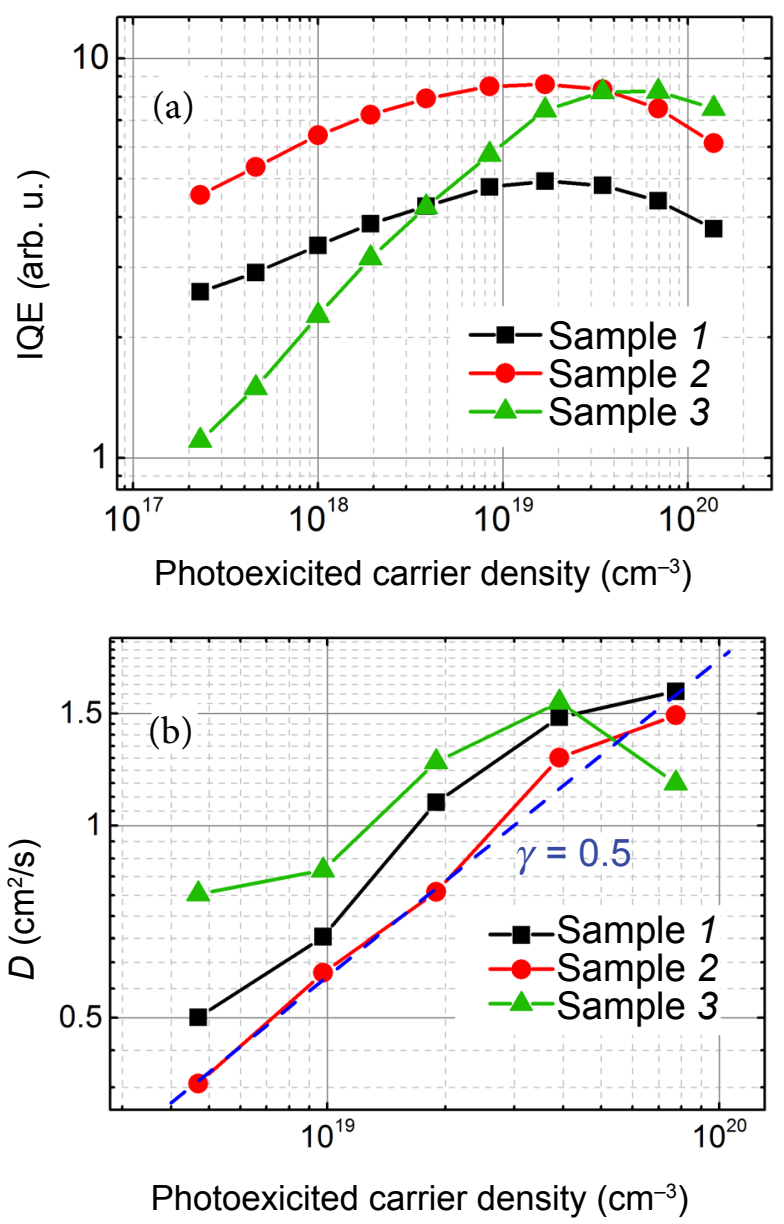

Fig. 6. IQE values (a) and diffusion coefficient (b) as a function of carrier density in the structures grown under continuous (sample 1) or pulsed growth (sample 2), and in the full LED structure (sample 3). 

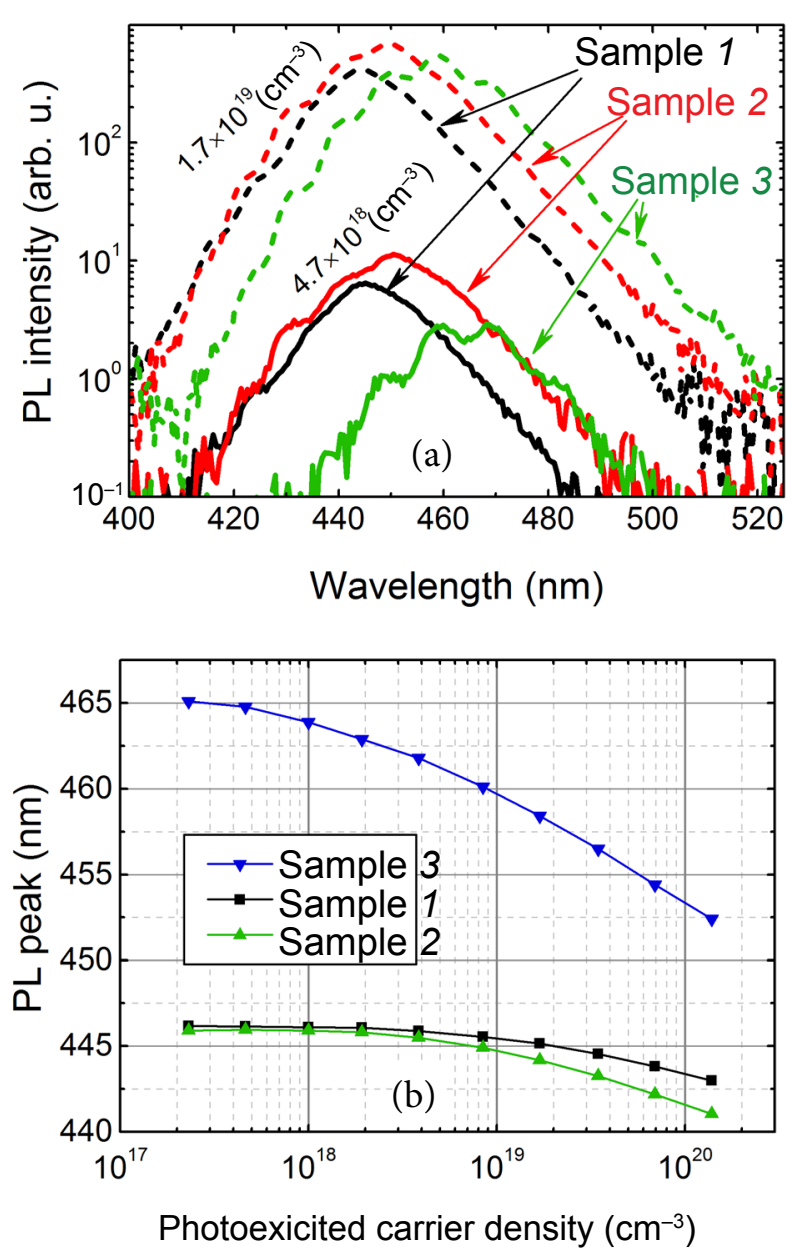

Fig. 7. PL spectra (a) and PL peak position vs carrier density (b) in samples 1,2 and 3.

like in the previous set, a larger blueshift can be a mixture of larger screening effects due to stronger electric fields and saturation of localized states. Both effects, however, have a similar negative influence on IQE at low excitations and are eliminated at high carrier densities, where IQE of the LED structure reaches the same peak value as in sample 2 . The latter fact indicates a relatively low defect density and low non-radiative recombination rate $A$. It is evidenced by TRPL measurements: $1 / A=\tau$ values are $13.5,27$, and $49 \mathrm{~ns}$ at $1.4 \times 10^{18} \mathrm{~cm}^{-3}$ in samples 1,2 , and 3 , respectively. Long lifetime and high IQE at high excitations indicate that the top p-GaN layer has a negligible negative effect on LED performance, which is often the case due to diffusion of $\mathrm{Mg}$ dopants to the active MQW area [33].

\section{Conclusions}

Insertion of the superlattice interlayer and the pulsed MOCVD growth were employed and yielded threeand two-fold enhancement of IQE in InGaN/GaN
QWs, respectively. A detailed investigation by timeresolved transient grating, photoluminescence, free carrier absorption, and differential transmission techniques was employed to analyze the physical origins of IQE increment and IQE droop at high carrier densities. The superlattice interlayer resulted in lower strain and smaller internal electrical field in the MQW samples. A crucial influence of carrier delocalization to IQE and its droop was evidenced by an inverse correlation between the IQE values and carrier diffusion coefficient: the increase in diffusivity resulted in the drop of IQE in all samples. A simple model based on the modified $A B C$ rate equation with the excitation-dependent $A$ term was used to account for increasing rate of nonradiative recombination with the excitation. The IQE droop was explained assuming the linear increase of both radiative and nonradiative recombination rates, together with the saturation of the radiative recombination coefficient due to phase-space filling. Finally, a LED structure with a $p$-type contact layer was grown with the peak IQE similar to that of the underlying MQW structure.

\section{Acknowledgements}

This work at Vilnius University was supported by the European Social Fund under Project VP1-3.1ŠMM-07-K-02-006.

\section{References}

[1] S. Nakamura, GaN growth using GaN buffer layer, Ipn. J. Appl. Phys. 30(10A), L1705 (1991), http:// dx.doi.org/10.1143/JJAP.30.L1705

[2] H. Amano, N. Sawaki, I. Akasaki, and Y. Toyoda, Metalorganic vapor phase epitaxial growth of a high quality GaN film using an AlN buffer layer, Appl. Phys. Lett. 48(5), 353-355 (1986), http:// dx.doi.org/10.1063/1.96549

[3] A. Sakai, H. Sunakawa, and A. Usui, Defect structure in selectively grown GaN films with low threading dislocation density, Appl. Phys. Lett. 71(5), 22592261 (1997), http://dx.doi.org/10.1063/1.120044

[4] S.J. Leem, Y.C. Shin, K.C. Kim, E.H. Kim, Y.M. Sung, Y. Moon, S.M. Hwang, and T.G. Kim, The effect of the low-mole InGaN structure and InGaN/GaN strained layer superlattices on optical performance of multiple quantum well active layers, J. Cryst. Growth 311(1), 103-106 (2008), http://dx.doi.org/10.1016/j.jcrysgro.2008.10.047

[5] S.P. Chang, C.H. Wang, C.H. Chiu, J.C. Li, Y.S. Lu, Z.Y. Li, H.C. Yang, H.C. Kuo, T.C. Lu, and S.C. Wang, Characteristics of efficiency droop in $\mathrm{GaN}$-based light emitting diodes with an insertion layer between the multiple quantum wells and 
n-GaN layer, Appl. Phys. Lett. 97(25), 251114 (2010), http://dx.doi.org/10.1063/1.3531957

[6] W.V.Lundin, A.E. Nikolaeva, A.V.Sakharova, E.E.Zavarina, G.A. Valkovskiy, M.A. Yagovkina, S.O. Usov, N.V. Kryzhanovskaya, V.S. Sizov, P.N. Brunkov, A.L. Zakgeim, A.E. Cherniakov, N.A. Cherkashin, M.J. Hytch, E.V. Yakovlev, D.S. Bazarevskiy, M.M. Rozhavskaya, and A.F. Tsatsulnikov, J. Cryst. Growth 315(1), 267-271 (2011), http://dx.doi. org/10.1016/j.jcrysgro.2010.09.043

[7] T.C.Wen,S.J.Chang, C.T.Lee, W.C.Lai, and J.K.Sheu, Nitride-based LEDs with modulation-doped $\mathrm{Al}_{0.12} \mathrm{Ga}_{0.88} \mathrm{~N}-\mathrm{GaN}$ superlattice structures, IEEE Trans. Electron Dev. 51(10), 1743-1746 (2004), http://dx.doi.org/10.1109/TED.2004.835985

[8] Y.J. Liu, T.Y. Tsai, C.H. Yen, L.Y. Chen, T.H. Tsai, and W.C. Liu, Characteristics of a GaN-based lightemitting diode with an inserted $\mathrm{p}-\mathrm{GaN} / \mathrm{i}-\mathrm{InGaN}$ superlattice structure, IEEE J. Quantum Electron. 46(4), 492-498 (2010), http://dx.doi.org/10.1109/ JQE.2009.2037337

[9] T. Jeong, H.J. Park, J.W. Ju, H.S. Oh, J.H. Baek, J.S. Ha, G.H. Ryiu, and H.Y. Ryu, High efficiency InGaN blue light-emitting diode with $>4 \mathrm{~W}$ output power at $3 \mathrm{~A}$, IEEE Photon. Technol. Lett. 26(7), 649-652 (2014), http://dx.doi.org/10.1109/ LPT.2014.2301874

[10]M. Moseley, B. Gunning, J. Greenlee, J. Lowder, G. Namkoong, and W.A. Doolittle, Observation and control of the surface kinetics of InGaN for the elimination of phase separation, J. Appl. Phys. 112(1), 014909 (2012), http://dx.doi.org/10.1063/1.4733347

[11]N. Dietz, M. Alevli, V. Woods, M. Strassburg, H. Kang, and I.T. Ferguson, The characterization of InN growth under high-pressure CVD conditions, Phys. Status Solidi B 242(15), 2985-2994 (2005), http://dx.doi.org/10.1002/pssb.200562246

[12] V. Woods and N. Dietz, InN growth by highpressures chemical vapor deposition: Real-time optical growth characterization, Mater. Sci. Eng. B 127(2-3), 239-250 (2006), http://dx.doi. org/10.1016/j.mseb.2005.10.032

[13] A. Kadys, T. Malinauskas, M. Dmukauskas, I. Reklaitis, K. Nomeika, V. Gudelis, R. Aleksiejūnas, P. Ščajev, S. Nargelas, S. Miasojedovas, and K. Jarašiūnas, Photoluminescence features and carrier dynamics in InGaN heterostructures with wide staircase interlayers and differently shaped quantum wells, Lith. J. Phys. 54(3), 187-198 (2014), http://dx.doi.org/10.3952/physics.v54i3.2959

[14] A. Kadys, T. Malinauskas, T.Grinys, M.Dmukauskas, J. Mickevičius, J. Aleknavičius, R. Tomašiūnas, A. Selskis, R. Kondrotas, S. Stanionytè, H. Lugauer, and M. Strassburg, Growth of InN and In-rich InGaN layers on GaN templates by pulsed metalorganic chemical vapor deposition, J. Electron. Mater. 44(1), 188-193 (2015), http://dx.doi. org/10.1007/s11664-014-3494-6
[15] S. Leyre, E. Coutino-Gonzalez, J.J. Joos, J. Ryckaert, Y. Meuret, D. Poelman, P.F. Smet, G. Durinck, J. Hofkens, G. Deconinck, and P. Hanselaer, Absolute determination of photoluminescence quantum efficiency using an integrating sphere setup, Rev. Sci. Instrum. 85(12), 123115 (2014), http://dx.doi.org/10.1063/1.4903852

[16] S. Valdueza-Felip, E. Bellet-Amalric, A. NúñezCascajero, Y. Wang, M.-P. Chauvat, P. Ruterana, S. Pouget, K. Lorenz, E. Alves, and E. Monroy, High In-content InGaN layers synthesized by plasma-assisted molecular-beam epitaxy: Growth conditions, strain relaxation, and In incorporation kinetics, J. Appl. Phys. 116(23), 233504 (2014), http://dx.doi.org/10.1063/1.4903944

[17] S. Park, T. Chung, J.H. Baek, and D. Ahn, Reduction of efficiency droop in green strain-compensated InGaN/InGaN light-emitting diodes grown on InGaN substrate, Jpn. J. Appl. Phys. 54(2), 022101 (2015), http://dx.doi.org/10.7567/JJAP.54.022101

[18] Y.L. Li, Y.R. Huang, and Y.H. Lai, Efficiency droop behaviors of InGaN/GaN multiple-quantum-well light-emitting diodes with varying quantum well thickness, App. Phys. Lett. 91(18), 181113 (2007), http://dx.doi.org/10.1063/1.2805197

[19]G. Sun, G. Xu, Y.J. Ding, H. Zhao, G. Liu, J. Zhang, and $N$. Tansu, Investigation of fast and slow decays in InGaN/GaN quantum wells, Appl. Phys. Lett. 99(8), 081104 (2011), http://dx.doi.org/10.1063/1.3627166

[20] M.J. Davies, T.J. Badcock, P. Dawson, M.J. Kappers, R.A. Oliver, and C.J. Humphreys, High excitation carrier density recombination dynamics of InGaN/ GaN quantum well structures: Possible relevance to efficiency droop, Appl. Phys. Lett. 102(2), 022106 (2013), http://dx.doi.org/10.1063/1.4781398

[21] N.I. Bochkareva, Y.T. Rebane, and Y.G. Shreter, Efficiency droop and incomplete carrier localization in InGaN/GaN quantum well light-emitting diodes, Appl. Phys. Lett. 103(19), 191101 (2013), http://dx.doi.org/10.1063/1.4828780

[22] R. Aleksiejūnas, K. Nomeika, S. Miasojedovas, S. Nargelas, T. Malinauskas, K. Jarašiūnas, Ö. Tuna, and M. Heuken, Carrier dynamics in blue and green emitting InGaN MQWs, Phys. Status Solidi B 252(5) 977-982 (2015), http://dx.doi.org/10.1002/ pssb.201451583

[23] J. Piprek, Efficiency droop in nitride-based light-emitting diodes, Phys. Status Solidi A 207(10), 2217-2225 (2010), http://dx.doi.org/10.1002/pssa.201026149

[24] J. Hader, J.V. Moloney, and S.W. Koch, Densityactivated defect recombination as a possible explanation for the efficiency droop in GaN-based diodes, Appl. Phys. Lett. 96(22), 221106 (2010), http://dx.doi.org/10.1063/1.3446889

[25]T. Malinauskas, A. Kadys, T. Grinys, S. Nargelas, R. Aleksiejūnas, S. Miasojedovas, J. Mickevičius, R. Tomašiūnas, K. Jarašiūnas, M. Vengris, S. Okur, V. Avrutin, X. Li, F. Zhang, Ü. Özgür, and H. Morkoç, 
Impact of carrier localization, recombination, and diffusivity on excited state dynamics in InGaN/GaN quantum wells, Proc. SPIE 8262, 82621S-1 (2012), http://dx.doi.org/10.1117/12.906488

[26] R. Aleksiejūnas, K. Gelžinytè, S. Nargelas, K. Jarašiūnas, M. Vengris, E.A. Armour, D.P. Byrnes, R.A. Arif, S.M. Lee, and G.D. Papasouliotis, Diffusion-driven and excitation-dependent recombination rate in blue InGaN/GaN quantum well structures, Appl. Phys. Lett. 104(2), 022114 (2014), http://dx.doi.org/10.1063/1.4862026

[27] T. Sadi, P. Kivisaari, J. Oksanen, and J. Tulkki, On the correlation of the Auger generated hot electron emission and efficiency droop in III-N lightemitting diodes, Appl. Phys. Lett. 105(9), 091106 (2014), http://dx.doi.org/10.1063/1.4894862

[28] A. David and M.J. Grundmann, Droop in InGaN light-emitting diodes: A differential carrier lifetime analysis, Appl. Phys. Lett. 96(10), 103504 (2010), http://dx.doi.org/10.1063/1.3330870

[29] J.I. Shim, H.S. Kim, D.S. Shin, and H.Y. Yoo, An explanation of efficiency droop in InGaN-based light emitting diodes: Saturated radiative recombination rate at randomly distributed In-rich active areas, J. Korean Phys. Soc. 58(3), 503-508 (2011), http://dx.doi.org/10.3938/jkps.58.503
[30]R. Aleksiejūnas, P. Ščajev, S. Nargelas, T. Malinauskas, A. Kadys, and K. Jarašiūnas, Impact of diffusivity to carrier recombination rate in nitride semiconductors: from bulk $\mathrm{GaN}$ to (In, Ga)N quantum wells, Jpn. J. Appl. Phys. 52(8 S), 08JK01 (2013), http://dx.doi.org/10.7567/JJAP.52.08JK01

[31]F. Hitzel, G. Klewer, S. Lahmann, U. Rossow, and A. Hangleiter, Localized high-energy emissions from the vicinity of defects in high-efficiency Ga $\mathrm{In}_{1-x} \mathrm{NGaN}$ quantum wells, Phys. Rev. B 72, 081309(R) (2005), http://dx.doi.org/10.1103/ PhysRevB.72.081309

[32]R. Aleksiejūnas, M. Sūdžius, T. Malinauskas, J. Vaitkus, K. Jarašiūnas, and S. Sakai, Determination of free carrier bipolar diffusion coefficient and surface recombination velocity of undoped GaN epilayers, Appl. Phys. Lett. 83(6), 1157-1159 (2003), http://dx.doi.org/10.1063/1.1599036

[33] D.M. Graham, P. Dawson, Y. Zhang, P.M.F.J. Costa, M.J. Kappers, C.J. Humphreys, and E.J. Thrush, The effect of a Mg-doped GaN cap layer on the optical properties of InGaN/AlGaN multiple quantum well structures, Phys. Status Solidi B 3(6), 2005-2008 (2006), http://dx.doi.org/10.1002/pssc.200565246

\title{
KVANTINIO NAŠUMO PAGERINIMAS InGaN KVANTINĖSE DUOBĖSE ĮTERPIANT SUPERGARDELE IR NAUDOJANTIS IMPULSINIU AUGINIMU
}

\author{
K. Nomeika, M. Dmukauskas, R. Aleksiejūnas, P. Ščajev, S. Miasojedovas, A. Kadys, S. Nargelas, \\ K. Jarašiūnas
}

Vilniaus universiteto Taikomuju mokslu institutas, Vilnius, Lietuva

\begin{abstract}
Santrauka
Vidiniokvantinio našumo(VKN) pagerinimas InGaN kvantinèse duobèse dèl supergardelès ịterpimo ir impulsinio auginimo pritaikymo ištirtas laikinès skyros optinių metodikų kombinacija. Supergardelès tarpsluoksnio iterpimas padidino VKN tris kartus, tai gali būti aiškinama sumažèjusiu vidiniu elektriniu lauku dèl mažesnių itempimų ir pakeistų lokalizacijos sąlygų. Impulsinio auginimo dèka VKN padidejo dvigubai, tikimiausiai dèl
\end{abstract}

geresnès defektų kontrolès struktūrose. Šviesos diodo darinys su viršutiniu $p$ tipo GaN kontaktiniu sluoksniu buvo pagamintas naudojant supergardelès tarpsluoksni ir impulsinị auginimą, tokiu būdu gautas toks pats maksimalus VKN kaip ir darinyje be kontaktinio sluoksnio. Tiesinès rekombinacijos koeficientas augo palaipsniui nuo žadinimo intensyvumo dèl krūvininkų delokalizacijos. Pasinaudojus tokia priklausomybe, buvo sèkmingai sumodeliuotas VKN smukimas. 